\title{
ACOUSTIC EMISSION AT FAILURE OF STEEL-TIMBER-CONCRETE COMPOSITE BEAMS
}

\author{
${ }^{1}$ István SZÜCS ${ }^{*}{ }^{2}$ Zsuzsa BALOGH, ${ }^{3}$ Rose HOLTZMAN \\ ${ }^{1}$ Department of Engineering and Information Technology, University of Pecs \\ Boszorkany u. 2, Pecs, 7624 Hungary, e-mail: szucs.istvan@mik.pte.hu \\ ${ }^{2,3}$ Department of Engineering, Metropolitan State University of Denver \\ P O Box 173362, Denver, CO 80217-3362, USA \\ e-mail: ${ }^{2}$ baloghz@msudenver.edu, ${ }^{3}$ rholtzma@msudenver.edu
}

Received 15 October 2018; accepted 25 March 2019

\begin{abstract}
Experimental investigations of laminated timber-concrete and steel-timber-concrete composite floor or bridge beams show that complex failure modes develop in such members. This paper presents acoustic emission investigation results that reveal the development of the failure modes in the steel-timber-concrete composite specimens subjected to short-term static ramploading. Accelerometers connected to a four channel dynamic signal analyzer continuously monitored the beam specimens during the load tests. Conventional techniques can be used for time domain data acquisition and evaluation of acoustic emission events generated in the structural member investigated, which contain thousands of independent signals to be processed, even if only in the audible frequency range. While the wavelet series of detected acoustic emission signals in the time domain produce a reliable amount of statistical information about the number and intensity of events, a frequency - time domain visualization may facilitate an advanced interpretation on the basis of spectrogram analysis. With on-site collection of data the methodology could allow for structural monitoring.
\end{abstract}

Keywords: Composite structural members, Experimental investigations, Acoustic emissions, Spectrogram analysis

\section{Introduction}

Laboratory load tests on laminated structural beam members [1], [2], [3], [4] for floors or bridges [5] consisting of a timber and a concrete layer interconnected with an adhesive, as it is shown in Fig. 1, were performed in the Structures Laboratory at

${ }^{*}$ Corresponding Author 
Metropolitan State University of Denver and, were reported in detail in prior papers [6], [7] that also described Carbon Fiber Reinforced Polymer - Laminated Timber Concrete CFRP-LTC beams. It was apparent that the failure modes are complex [6], [7], [8] and more related data is needed. Subsequently, due to the brittle-type failure of the Laminated Timber-Concrete (LTC) beams, a steel reinforcement was added (embedded in) to the tension fibers of the timber layer (also replacing the CFRP), and the load testing was completed in Spring 2018.
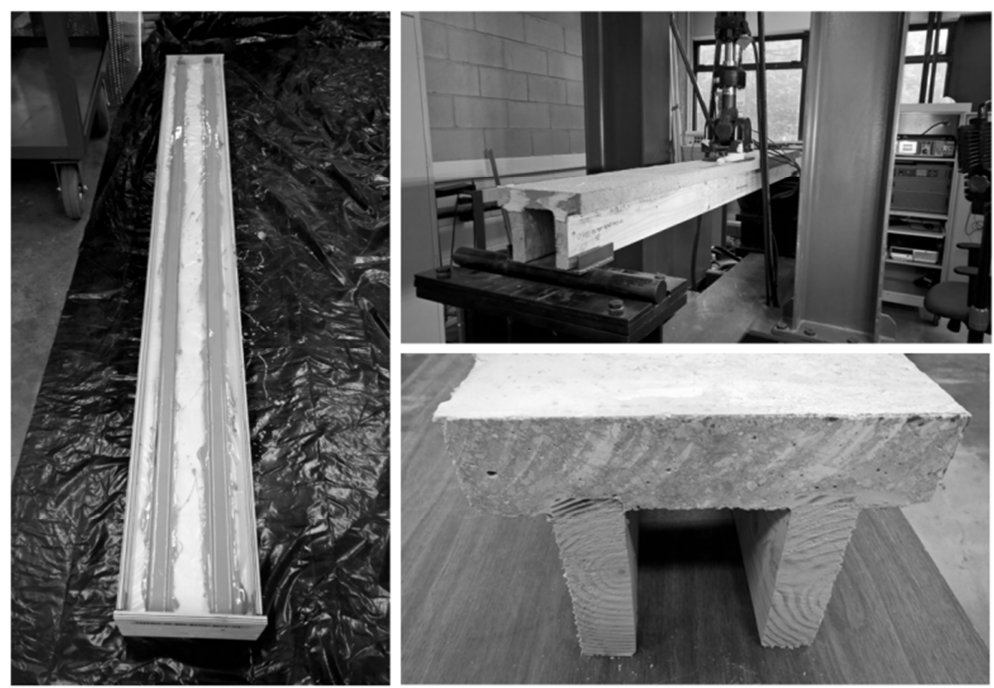

Fig. 1. Typical $2.4 \mathrm{~m} \mathrm{LTC} \mathrm{specimen;} \mathrm{adhesive} \mathrm{applied} \mathrm{prior} \mathrm{to} \mathrm{fresh} \mathrm{concrete} \mathrm{placement} \mathrm{(left);}$ load test setup (top-right); composite cross-section (bottom-right)

\section{Experimental program}

To better map the failure modes of Steel-Laminated-Timber-Concrete (S-LTC) composite specimens, acoustic emission investigations were conducted during load tests of 5 LTC beams, in part reported in a prior paper [6], using four accelerometer sensors. Conventional techniques can be used for time domain data acquisition and evaluation of Acoustic Emission (AE) events generated in the structural member investigated [9], [10], [11].

The AE activity monitoring of a failure test may result in the processing of thousands of independent signals in and far beyond the audible frequency range. The usual patterns of the waveform series of detected AE signals in the time domain produce a reliable amount of information only about the number and intensity of events in connection with the emitted energy releases. The data processing with a frequency time domain visualization proved to be a more sophisticated support of interpretation by means of a waterfall-type spectrogram analysis providing for a supplementary tool to visualize and distinguish some of the failure mechanisms of composite beams. 
As it is indicated in [6] the experimental program was performed with a Brüel/Kjaer PHOTON+TM dynamic signal analysis system, converting a laptop computer into an instrument-quality multi-channel analyzer with $115 \mathrm{~dB}$ dynamic range and with a $84.2 \mathrm{kHz}$ real-time rate. This data collection system was equipped with four $\mathrm{B} / \mathrm{K} 4397$ accelerometers with resonance frequencies between $45.7-55.7 \mathrm{kHz}$, that were installed in the same configuration on all of the laminated beams specimens. For mechanical coupling of the sensors to the beams, a mounting wax was used. The accelerometers, with built-in preamplifiers, connected to the data acquisition system by means of Teflon insulated double-screened cable (type AO1381). Voltage ranges from $10 \mathrm{mV}$ to $10 \mathrm{~V}$ were provided by programmable gain stages on the inputs. This design, together with the 24-bit resolution, resulted in an extremely low noise floor; a requirement for acoustic measurements; and high accuracy. The quick measurement setup, combined with real time indication of the detected signals, enabled a continuous monitoring validation, recording, and post-processing of the data both in the time and frequency range.

Fig. 2 shows a typical acceleration - frequency - time function (right, in black field) and the relating Fast Fourier Transformation (FFT) spectrograms of the AE activity during the last 25 seconds of a loading test processed by means of RT Pro ${ }^{\text {TM }} 7.2$ software on two parallel channels (left: G1(f) in a lower pass- and G2(f) in an extended frequency range).

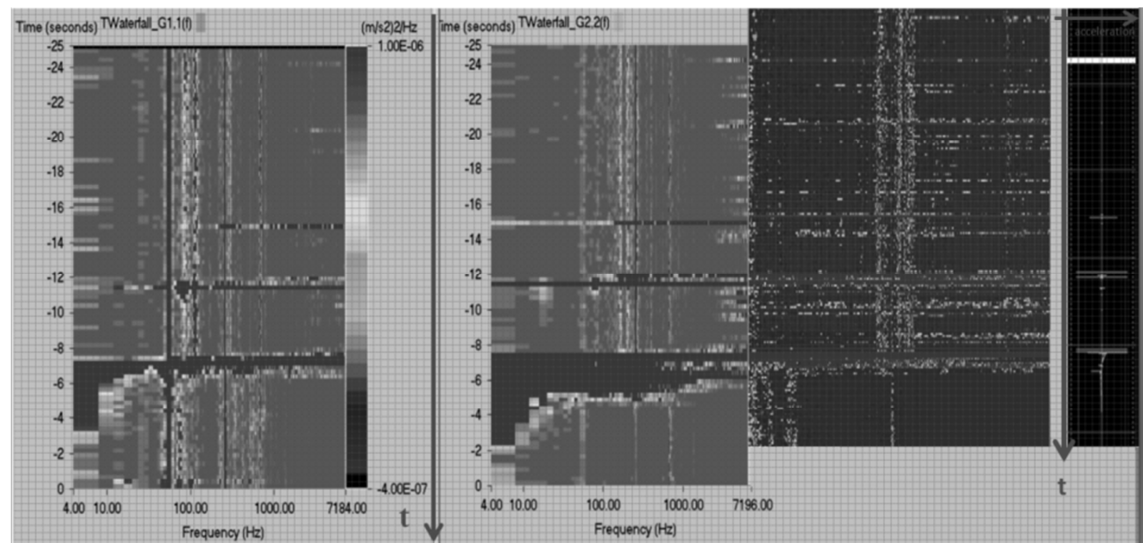

Fig. 2. Typical spectrogram of the AE activity during failure

\section{Results}

The four-channel monitoring of the complete load test process ranging to 700 seconds produced a considerably higher amount of AE signals in the final stage of the observation approaching the failure as it is shown in Fig. 3. Therefore, the traditional evaluation focused on the last 100 seconds of the data, specifically on the distribution of the number and intensity of AE signals generated in the investigated S-LTC beams (BM4, BM5 - earlier [6] and recently BM9 - in 2018). 


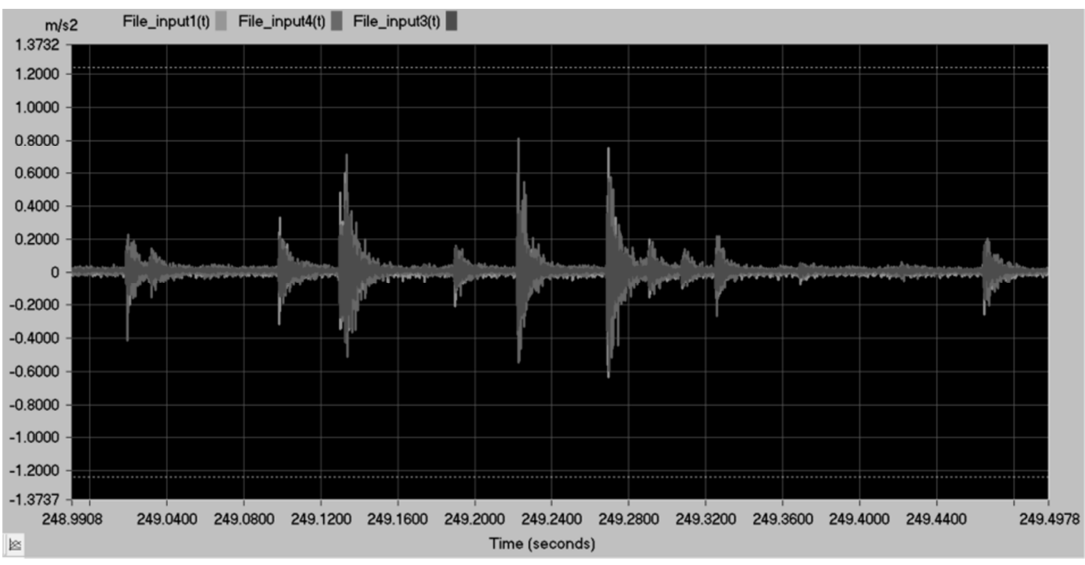

Fig. 3. Typical acceleration - time plot of AE activity during the final stage of failure

\subsection{Conventional processing}

The main significant features of the detected AE signals (number of $\mathrm{AE}$ signals/channels, AE (peak) intensity, average intensity/AE) derived from the last 100 seconds of the loading period recorded for S-LTC beams are summarized in Table 1. The AE intensity was defined as the peak values of each independent burst type transient. The continuous type acoustic emissions in the observed frequency range were disregarded, not because of the negligible number, but because of the very low levels and signal/noise ratio of them.

Table I

Main parameters of the detected AE signals prior to S-LTC beams failure

\begin{tabular}{|c|c|c|c|c|c|}
\hline & \multicolumn{2}{|c|}{ Number of AE signals/Ch. } & \multicolumn{2}{|c|}{ AE (peak) Intensity [m/ $\left.\mathrm{s}^{2}\right]$} & $\begin{array}{c}\text { Average Int/AE } \\
{\left[\mathrm{m} / \mathrm{s}^{2}\right]}\end{array}$ \\
\cline { 2 - 5 } & Total & Average/s & Total & Average/s & 6.43 \\
BM4 & 132 & 1.52 & 848.35 & 9.75 & 3.31 \\
BM5 & 160 & 1.48 & 530.29 & 4.91 & 6.12 \\
BM9 & 148 & 1.73 & 923.50 & 6.93 & \\
\hline
\end{tabular}

While the correlation coefficients between AE intensities are higher than 0.95 for any combination of different beams behavior in the final 10 seconds the correlation between $\mathrm{AE}$ intensity and number is much less significant as summarized in Table II. The higher values calculated and summarized in Table II are restricted to the short time domain $(-5 \mathrm{~s})$ represented by stable increasing rates preceding the impending final failure.

\subsection{Spectrogram processing and evaluation}

By means of FFT spectrogram analysis the sampled data, in the time domain was broken into segments, which usually overlap, and Fourier transformed to calculate a 
magnitude - frequency spectrum for each segment. The series of spectra are laid side by side to form an image like a three-dimensional surface.

\section{Table II}

Correlation of AE intensity and number prior to S-LTC beams failure

\begin{tabular}{|c|c|c|c|}
\hline $\begin{array}{c}\text { Time domain } \\
\text { before final } \\
\text { failure [s] }\end{array}$ & \multicolumn{3}{|c|}{ Correlation coefficient between AE intensity and number } \\
\cline { 2 - 4 } & BM4 & BM5 & BM9 \\
\hline-5 & 0.77 & 0.79 & 0.69 \\
-10 & 0.34 & 0.85 & 0.31 \\
-15 & 0.25 & 0.12 & 0.11 \\
\hline
\end{tabular}

Fig. 4 shows the acceleration - time function (right) and the relating FFT spectrogram (left) of the AE activity in BM9 during the few seconds of loading test. The FFT spectrogram, displaying large amounts of compacted information is a very useful tool in the efficient evaluation of load test history. During the investigation of the BM4-9 beams we have recorded thousands of AE signals in the measured frequency range. In the analysis, focus was given to the AE signals, whose numbers/channels are indicated in the left column of Table $I$. The vast compressive capacity of spectrogram analysis proved to be a productive instrument in finding new conclusions. Fig. 4 illustrates a short time ( 3.7 seconds) of spectrogram from the AE database of BM9. The spectrogram presents the sequential appearance of AE-s over time and provides information about the frequency contents of each signal.

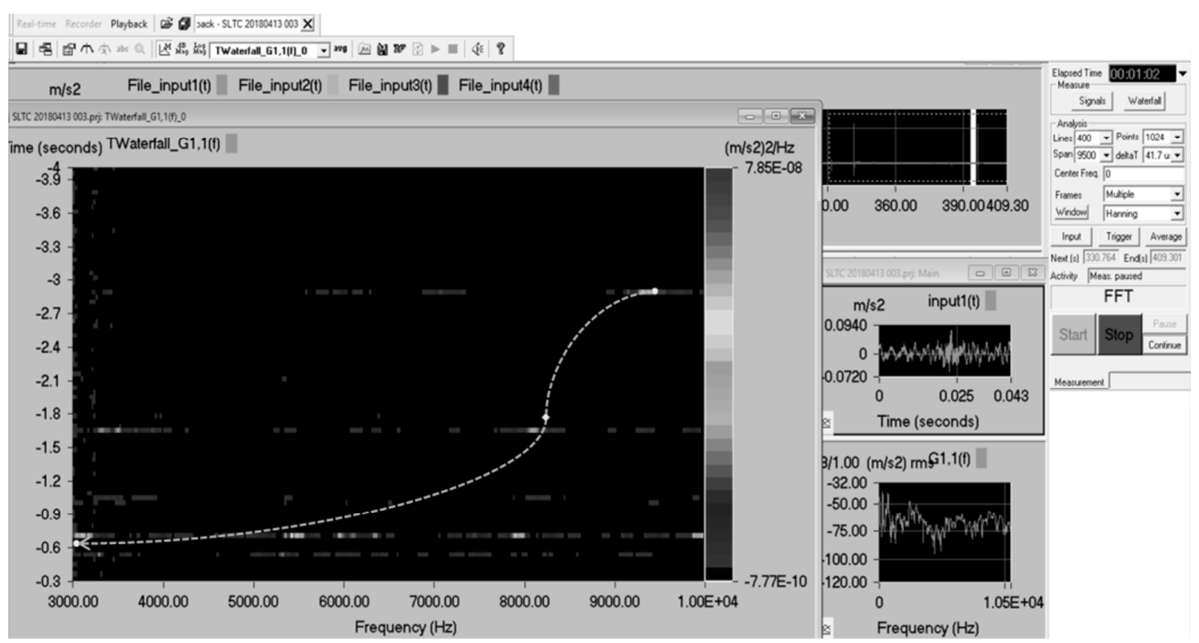

Fig. 4. Spectrogram plot of AE activity prior to the final stage of failure

Analyzing the corner frequencies of the succeeding individual AE signals, each of them represent an emitted energy release originating from a given source size (R), 
which is inversely proportional to the corner frequency (f) and directly to the wave propagation velocity. The positioning of accelerometers allows for the use of the following formula [12], containing the share wave velocity $\left(v_{s}\right)$ value: $R=2.34 \times v_{s} / 2 \pi f$.

The estimated source size growth range (due to the corner frequency drop from 10 $\mathrm{kHz}$ to $2 \mathrm{kHz}$ ) is between $8-40 \mathrm{~cm}$. Fig. 5 illustrates the documented final size.

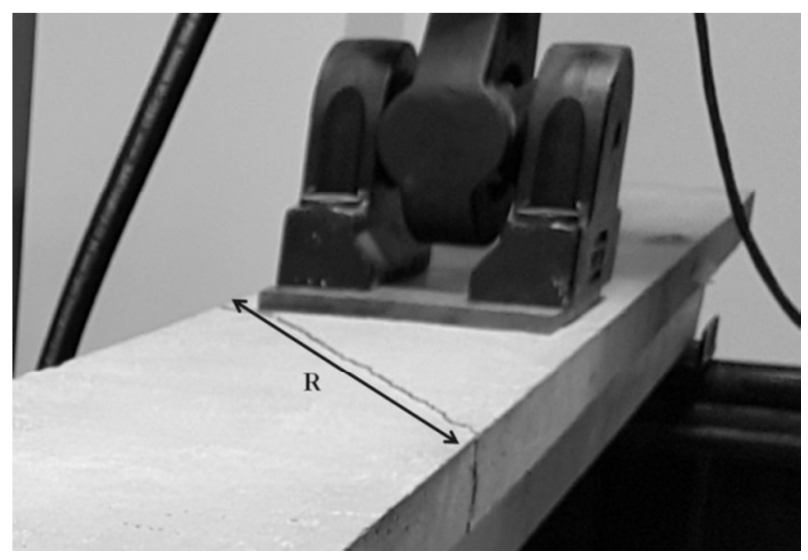

Fig. 5. The final failure size of BM9 after the load test

In connection with the developing failure mechanism in the investigated beam specimens reflected by the AE spectrogram patterns studied, different types could be identified and classified as demonstrated in Fig. 6.

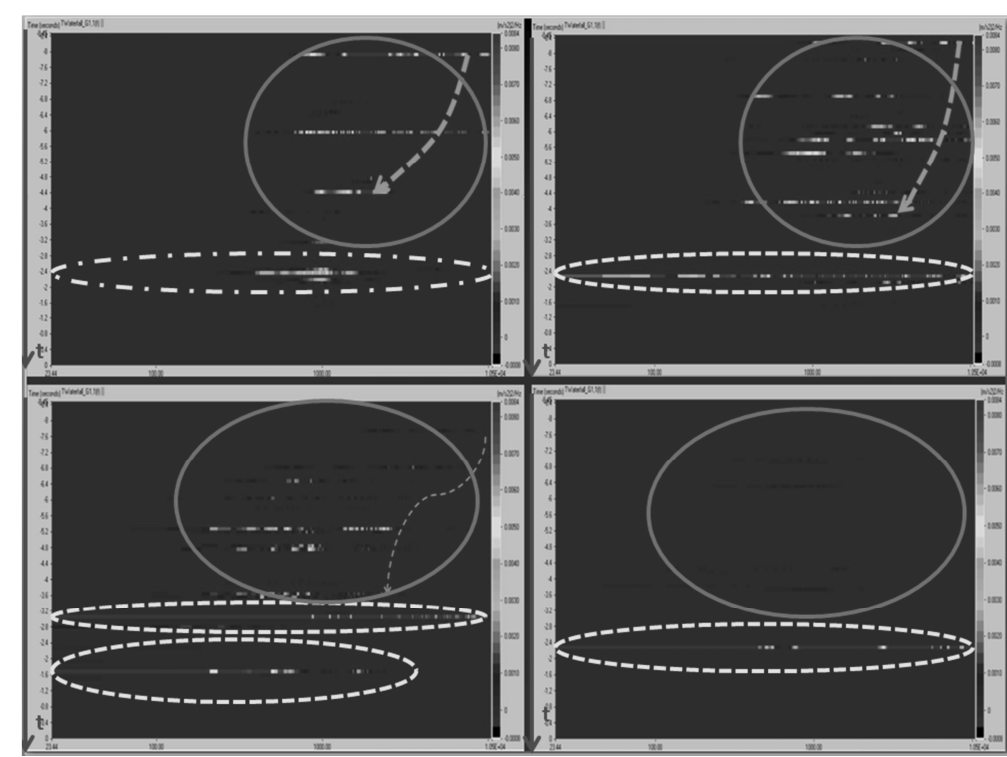

Fig. 6. Identifying and categorizing the developing failure mechanisms [6]

Pollack Periodica 14, 2019, 2 
Each of the four components of the Fig. 6 represents an identified type of a partial failure process (distinguished by means of AE monitoring) inside a given part of the test beam. Each of them can be divided into two main domains of phenomena: precursorand closing range of failures. The closing failures (terminating - temporarily - the partial lifecycle of an evolving fissure passing abruptly into a more significant failure in size and with an energy release substantially exceeding the preceding ones) are encircled by dashed lines, while the precursor failures are represented by the forerunning AE series encircled by continuous lines. The dotted-dashed line shows a spectrogram segment of a closing acoustic emission in a narrower frequency range, representing either the lack of closing failure or just a smaller energy release.

The brighter the spectrum is, as value ranges of the detected AE signal acceleration, the higher the energy released in the process.

\section{Conclusions}

While the wavelet series of detected acoustic emission signals in the time domain produce a reliable amount of statistical information about the number and intensity of events, frequency-time domain visualization may facilitate an advanced interpretation on the basis of spectrogram analysis.

The performed spectrogram analysis of S-LTC load tests demonstrated and confirmed that in the final stage of the individual failures the significant drop of corner frequencies of the succeeding AE signals, (representing an inverse proportion to the rupture sizes of their sources,) could be directly observed and analyzed. The wider frequency ranges (between their lower and upper corner frequencies) of the closing failures are the AE-imprints of a partial (or final) cycle ending in a failure mechanism progression.

With on-site collection of data, the methodology allows for structural monitoring.

\section{Acknowledgements}

The research was performed within the framework of the institutional cooperation between the authors' universities. The authors are grateful to their students assisting with the laboratory experiment setup during spring 2018.

\section{Open Access statement}

This is an open-access article distributed under the terms of the Creative Commons Attribution 4.0 International License (https://creativecommons.org/licenses/by/4.0/), which permits unrestricted use, distribution, and reproduction in any medium, provided the original author and source are credited, a link to the CC License is provided, and changes - if any - are indicated. (SID_1) 


\section{References}

[1] Balogh J. Laminated wood-concrete structural members, Pollack Periodica, Vol. 8, No. 3, 2013, pp. 79-86.

[2] Henrique J., Oliveira J. D., Miguel F., Oliveira M. D., Alexandra C., Oliveira L. D., Cachim P. B. Glued composite timber-concrete beams, I: Interlayer connection specimen tests, ASCE, Journal of Structural Engineering, Vol. 136, No. 10, 2010, pp. 1236-1245.

[3] Henrique J., Oliveira J. D., Miguel F., Oliveira M. D., Alexandra C., Oliveira L. D., Cachim P. B. Glued composite timber-concrete beams, II: Analysis and tests of beam specimens, ASCE, Journal of Structural Engineering, Vol. 136, No. 10, 2010, pp. 12451254.

[4] Balogh J., Fragiacomo M., Gutkowsky R., Atadero R., Ivanyi P. Low-to-high cycle fatigue behavior of wood-concrete composite beams with notched interlayer connections, Pollack Periodica, Vol. 8, No. 1, 2013, pp. 3-14.

[5] Jutila A. Wood concrete composite bridges - Finnish specialty in the Nordic Countries, Proceedings of the International Conference Timber Bridges, Lillehammer, Norway, September 12-15, 2010, 2010, pp. 383-392.

[6] Szucs I., Balogh J., Holtzman R. Acoustic emission investigation of laminated timberconcrete beam load tests, International Journal of Computational Methods and Experimental Measurements, Vol. 5, No. 6, 2017, pp. 884-893.

[7] Balogh J. High performance CFRP-timber concrete laminated composite members, Proceedings on World Conference on Timber Engineering, Vienna, Austria, 22-25 August 2016, pp. 4320-4327.

[8] Clouston P., Quaglia C. Experimental evaluation of epoxy based wood-concrete composite floor systems for mill building renovations, International Journal of the Constructed Environment, Vol. 3, 2013, pp. 63-74.

[9] Varner D., Cerny M., Varner M., Fajman M. Possible sources of acoustic emission during static bending test of wood specimens, Acta Universitatis Agriculturae Et Silviculturae Mendelianae Brunensis, Vol. LX, No. 3, 2012, pp. 199-206.

[10] Kaphle M. R. Analysis of acoustic emission data for accurate damage assessment for structural health monitoring applications, $P h D$ thesis, Queensland University of Technology, 2012.

[11] Szucs I., Deak F. Examination of a granitic host rock behaviour around underground radwaste repository chambers based on acoustic emission datasets, In: Rock mechanics and rock engineering: From the past to the future, Ulusay R., Aydan O., Gercek H., Hindistan M. A., Tuncay E. (Eds.) Taylor \& Francis Group, London, 2016.

[12] Hardy H. R. Jr. Acoustic emission/Microseismic activity, Taylor \& Francis, Vol. 1, 2003. 